\title{
Developing A Framework For Writing Skill: A Corpus-Based Analysis Of The Written Argumentative Essays
}

\author{
Anita Kanestion ${ }^{a}$,Manvender Kaur Sarjit Singh ${ }^{a^{*},}$ Sarimah Shamsudin ${ }^{b}$ \\ ${ }^{a}$ Awang Had Salleh Graduate school, Universiti Utara Malaysia, Sintok, Kedah, Malaysia \\ ${ }^{b}$ Language Academy, Universiti Teknologi Malaysia, 54100 Kuala Lumpur, Malaysia \\ *Corresponding author: manvender@uum.edu.my
}

\begin{abstract}
Most scholars have studied written discourse both in academic and professional setting within the scope of genre-based analysis, which demonstrate an increase interest in analysing the rhetorical structure of written texts. Conversely, there is a dearth of research in Malaysia that explains the rhetorical structure of argumentative essays from a genre analysis perspective. This paper introduces a genre-based corpus analysis using a compiled representative corpus of the argumentative essay for developing a rhetorical structure, also known as, an analytical framework to enhance the students' writing skills. The compiled representative corpus was consisted of 24 argumentative essays. As a qualitative study, a corpus-based analysis is employed to explore the distinguished move patterns used in the argumentative essays. Using Hyland's (1990) 11 move pattern as an analytical framework of the argumentative essay, this study revealed a list of moves and steps which were signaled by the linguistic features. Consequently, there were altogether 9 moves and 14 steps were identified in the three stages, namely Introduction, Argument and Conclusion. However, the moves used by the pre-university students in the study did vary from the model as new moves were marked in each stage. Pedagogically, the findings of this study were expected to guide in developing a framework for writing skills.
\end{abstract}

Keywords: Argumentative essays; corpus-based analysis; Hyland's analytical model

(C) 2017 Penerbit UTM Press. All rights reserved

\subsection{INTRODUCTION}

Academic texts of multiple disciplines are analysed using different types of text analysis approaches as they assist to uncover the written conventions. However, most of the approaches are mainly concerned to study the language use at the lowest unit, which involves the use of part-of-speech. For instance, register analysis is an approach used to study the language at word level and sentence level. To date, most of the researchers employ genre analysis as an instrument to analyse and teach the language required in both academic and professional settings. Swales (1990) has defined genre analysis as a method of studying the written and spoken discourse in order to rationalize the reasons why genre texts have acquired certain features. In other words, it examines the writer's communicative purpose. Bhatia (1993)further explains that genre analysis is an analytical framework which exposes the correlations of form and function meanwhile Promwani(2010) argues that it also adds to the understanding of the cognitive structuring of knowledge in particular areas of language use. In short, genre analysis is a sophisticated way of analysing the written and spoken discourse at the textual level and linguistic level. Viewing the fundamental aspect of genre analysis, Swales (1990), who investigated the introduction of research articles, under the domain of English for Specific Purposes (ESP), has highlighted a regular pattern of 'moves' and 'steps'. A move is classified as a unit that functions within a segment of a text and this directly provides an overall purpose of the text(Connor\&Mauranen, 1999). However, to realize the functions of the moves involve, writers need to employ a step or a combination of steps (Bhatia, 1993). Therefore, moves and steps are considered as the strategies used by a writer to shape the skeleton of a genre (Mobasher\& Mohamad Ali, 2015).

To date, the emergence of 'moves' and 'steps'in Swales' (1990) model of Create A Research Space (CARS), has motivated most researchers to analyse different types of texts within the area of English for Specific Purposes (ESP), including academic and professional texts, namely the introduction of research articles (Swales, 1990; Ina, Aizan\& Noor Hashimah, 2015); abstracts ( Tseng, 2011; San \& Tan, 2012; Chalak\&Norouzi, 2013; Abarghooeinezhad\&Simrin, 2015); book preface (Abdollahzadeh\&Salarvand, 2013; Ali, Muhammad \&Asim, 2015); book reviews (Nodoushan\&Montazeran, 2012), proposals and theses (Jalilifar, Firuzmand\&Roshani, 2011; Choe\& Hwang, 2014), problem statement (Vahid, Zahra, Sara \&NurIzyanSyamimi, 2016), research articles (Maswana, Kanamaru\&Tajino, 2015; Kanoksilaphatam, 2003), and work procedures of engineers (Manvender, 2014). Researchers in these studies have focused on rhetorical structure. Nevertheless, having reviewed aforementioned studies on the academic texts, one will find out that there is a scarcity of research in the rhetorical structure of argumentative essays.

Not forgetting, in the same era as Swales (1990), Hyland (1990), proposed an analytical framework of an argumentative essay using 65 essays of non-native speakers, having three stages and several moves, except for steps. This preliminary study wasconducted byadopting 'categories analysis' and the Birmingham model of spoken discourse (Hyland, 1990), which similarly ledto the realization of moves. These moves are considered to be identified using a bottom-up approach (Vahid, Zahra, Sara \&NurIzyanSyamimi, 2016; San \& Tan, 2012; Swales, 1990), where the linguistic features, the smallest unit, in each sentence used to determine the moves in the 65 argumentative 
essayswritten by the L2 learners.However, the study failed to provide the linguistic features that helped in realizing the existence of moves in the essays.Hyland (1990)also concluded that more researches were needed to develop the respective model. In a study in Pakistan, Imtiaz and Mahmood (2014) adopted Hyland's (1990) model as an analytical tool. Using 33 argumentative essays, a compiled representative corpus, produced by college and university students at ICLE (The International Corpus of Learner English) the researchers explored the move structures of the essays and identify the learners' weaknesses in writing. The findings revealed that the rhetorical structure employed by the writers differs from Hyland's (1990) model as two new moves were identified (Contradictory and Recommendation) and the changes in terms of obligatory and optional moves were realized. These differences could probably indicate that such convention in writing is unknown to the L2 writers (Imtiaz and Mahmood, 2014).Additionally, the findings also showed that Hyland's model could be employed to highlight the differences and similarities as well as the weaknesses of the students related to the rhetorical structure of an argumentative essay. A comparative study conducted by Liu (2015) also used Hyland's (1990) model to examine the moves and wrap-up sentences in the concluding paragraphs of English expository essays produced by three groups of Chinese students; first year, second year and third year. For this purpose 184 essays were analysed and the results exposed that there were differences in using moves in Chinese rhetorical structure in writing a concluding paragraph in comparison with English model essays. Even though Liu (2015) attributed these differences to L1 rhetorical transfer, the frequency and quality of the moves could improve when the level of proficiency increased. This study only provided a greater understanding about the cultural differences (Connor andMauranen, 1999; Matsuda, 1997). Like Hyland (1990), Imtiaz and Mahmood (2014) and Liu (2015) also failed to provide insight on the linguistic features that were used to signal the moves. To sum up, the need for the students to learn the rhetorical structure of argumentative essays still exist (Reza \&Atena, 2013); particularly in Malaysia. Due to its limitation, the present study aims to address the possibility of carrying out move analysis in developing a rhetorical structure of argumentative essay using Hyland's (1990) analytical framework.

\subsection{METHODOLOGY}

\section{Participants}

Purposive sampling method is believed to provide an extensive scope of issues to be explored (Lincoln and Guba, 1985), especially in qualitative researches. Therefore, the participants for a purposive sampling are selected based on specific characteristics such as location, gender, race and easy accessibility to data. The participants of this present study were employed using a purposive sampling approach due to the criteria to be researched upon; they were all pre-university students who would be taking the Malaysian University English Test (hereafter MUET) in November as well as the expectation of them in producing the written argumentative essays within the stipulated time (50 minutes). For the purpose of this study, the MUET past year's argumentative essay question was used in the classroom and the written essays were rated by two raters who had the experience of teaching and marking for more than 10 years. To fit the aim of the study that is to develop a framework for writing an argumentative essay, Band 4, 5 and 6 essays were selected and compiled as a representative corpus. A representative corpus, according to Manvender, Yasmin and Sarimah (2012), refers to a learner corpus, which is compiled and meant to be used for a specific purpose. The selection was made to provide insights from good to best argumentative essays because Band 4,5 and 6 writers were known as the proficient user of the L2 or writers at an above satisfactory level (Malaysian Education Council Report, 2014: p. 8). The corpus of the present study comprised of 24 argumentative essays produced by the pre-university students in a pre-university institution in Malaysia. There are 10 essays with the score of Band 4 and Band 5 each and 4 essays with Band 6 . They were saved as a raw corpus B6AE_1, B5AE_1, B4AE_1, which refer to the Band 4, 5 and 6 essays produced by the students No.1.

\section{Analytical Framework}

As it was noted, Hyland's (1990) framework was employed to guide the researchers in identifying the moves and steps used in the argumentative essays. The analytical framework suggested that there were 10 moves involved in producing an argumentative essay. The reason for adopting Hyland's (1990) framework is that it is comprehensive and clear to be used as a framework of analysis as each move is clearly defined (Table 1). For each move, Hyland has provided examples that would assist the writers to identify moves more concisely. Moreover, the framework was also developed using second language learners (L2) in a second language setting. However, limited studies had utilized this framework extensively.Using this comprehensive model, a list of moves and steps were identified using the representative corpus of argumentative essays composed by the pre-university students.

Table 1 Hyland's (1990) analytical framework

\begin{tabular}{ll}
\hline Stage & Moves \\
\hline Thesis & (Gambit) \\
Introduces the proposition & Attention Grabber - controversial statement of dramatic illusion. \\
to be argued & (Information) \\
& Presents background material for topic contextualization. \\
& Proposition \\
& Furnishes a specific statement of position. \\
& (Evaluation) \\
& Positive gloss - brief support of the proposition \\
& (Marker) \\
& Introduces and /or identifies a list.
\end{tabular}




\begin{tabular}{|c|c|}
\hline \multirow{5}{*}{$\begin{array}{l}\text { Argument } \\
\text { Discusses grounds for } \\
\text { thesis. } \\
\text { (four move argument } \\
\text { sequence can be repeated } \\
\text { indefinitely) }\end{array}$} & Marker \\
\hline & $\begin{array}{l}\text { Signals the introduction of a claim and relates it to the text } \\
\text { (Restatement) }\end{array}$ \\
\hline & Rephrasing or repetition of proposition. \\
\hline & Claim \\
\hline & States reason for acceptance of the proposition. \\
\hline & Support \\
\hline & States the grounds which underpin the claim. \\
\hline \multirow{7}{*}{$\begin{array}{l}\text { Conclusion } \\
\text { Synthesized discussion } \\
\text { and affirms the validity of } \\
\text { the thesis. }\end{array}$} & (Marker) \\
\hline & Signals conclusion boundary. \\
\hline & Consolidation \\
\hline & Presents the significance of the argument stage to theproposition. \\
\hline & 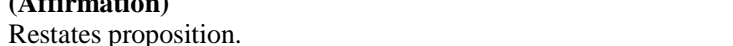 \\
\hline & (Close) \\
\hline & Widens context or perspective of proposition. \\
\hline
\end{tabular}

\section{Analysis Procedures}

The corpus-based analysis in this study involved several steps. The initial step in analysing the corpus was the division of the essays into three stages, Introduction, Argument, and Conclusion using Notepad++ 6.9.2 (2016). It is free online software, which is used for tagging the moves manually in the texts (Manvender, 2014).Next, the identification of the moves was done based on individual sentences. The researcher and a rater identified the moves based on bottom-up and top-down approaches. If there were some disagreement in a particular move both rater and researcher would discuss and reach an agreement as to ensure the inter-rater reliability at an acceptable value. Bottom-up approach is when the identification of the moves is determined clearly by the linguistic features. The examples below show the linguistic feature (in bold) that distinguished the moves in the texts.

\section{Therefore, I agree a person can determine his own success. (Stating a position) (B4AE_8)(M3S3a)}

2. As a student, success means score with flying colours in the exams or perhaps being awarded with a scholarship to further his studies. (Defining the key word) ( B4AE_2)(M2S2a)

As assured in the examples, the usage of verbs (in bold), 'I agree.....' and 'success means.....'explicitly state the types of moves used.Evidently, both agree and means indicated that they belong to 'Stating a position' and 'Defining the key word'. When the linguistic signal was unclear or absent, top-down approach was used.Here, the moves were distinguished based on the meaning of a sentence or a few sentences to define which move it refers to. This is shown in the examples below,

3. Many people dream of an idyllic lifestyle where security systems are a cumbersome monetary liability and the sight of women prowling the streets at night on the way to buy various goods at a local night market as common as swatting a mosquito in summer.And yet, reality beckons us from our wistful imaginations to face the cold hard facts; where security systems are part and parcel of daily operations and that seeing a woman wandering the streets at night means reading about her in the papers days later for reasons too vile to replicate here.(Describing an issue related to the topic) (B6AE_4) (M1S1a)

4. "There are no secrets to success. It is the result of preparation, hard work and learning from failure"-Colin Powell(Stating an expert's opinion) (B5AE 5) (M2S2c)

The noun phrases (dream of an idyllic lifestyle, monetary liability, and the sight of women prowling the streets, wistful imaginations) with the presence of verb phrases (buy various goods, swatting a mosquito, face the cold hard facts, reading about her in the papers) in example 3, distinguished the move as an attention grabber in which the issues related to the topic was described. Meanwhile, the noun phrases in example 4 (no secrets, result of preparation, hard work and learning from failure, Colin Powell), recognized the sentence as 'Providing an expert's opinion'.

Generally, it can be said that moves can be distinguished by structures ranging from a word, a phrase, a clause or even a few sentences. After completing the identification of moves and steps using the comprehensive model, the researcher had created a list coding to indicate the moves and steps. For instanceM1S1a, M1 indicates Move 1 whereas S1a indicates Step 1a. Therefore, with Hyland's (1990) comprehensive model, it was hoped the findings from the analysis would in some way provide insights on how the pre-university students write argumentative essays.

\subsection{RESULTS AND DISCUSSION}

To begin with, the moves were identified according to three stages, namely Introduction, Argument, and Conclusion. Table 2 indicated the rhetorical structure of the first stage of an argumentative essay. Contrary to Hyland's model, the first stage was identified as Introduction by the researchers as in Malaysia, the Thesis stage is frequently known as an introductory paragraph. Thus, the researchers made some modification to cater the students and teachers needs. The findings revealed that the pre-university students produced three moves to compose 
the first stage, namely 'Providing attention grabber', 'Providing background information' and 'Announcing position'.These moves were realized and shaped by a few steps. For example, Move 1 Providing attention grabber was realized based on a step which was 'Describing the issue(s) related to the theme or topic'. Hyland (1990) also addressed this move as Gambit move which was employed to grab the attention of the readers.Meanwhile Move 2 'Providing background information' was realized based on the combination of three steps 'Defining the key word (s)/ theme', 'Stating expert's opinion'and 'Providing driving questions to contextualize the topic/issue'.This move was known as Information move in Hyland's model which had a similar function, providing information. Move 3 'Announcing position' was realized based on two steps, which were 'Stating a stand or position' and 'Indicating reasons or main ideas'. In Hyland's model this move was realized as proposition, evaluation and marker. However, marker move was not found to be employed by the pre-university students in their essays.

Table 2 Rhetorical structure of introduction

\begin{tabular}{ll}
\hline StageMoves & \\
\hline Introduction & $\begin{array}{l}\text { Move 1: Providing attention grabber } \\
\text { Steps }\end{array}$ \\
& 1a. Describing the issue (s) related to the theme \\
Move 2: Providing background information \\
Steps
\end{tabular}

Based on Table 3, the first step (S1a: Describing the issue related to the theme) was signaled by the noun phrases (newspapers, news channel, reports of crimes, actual report, outrageous crimes, prevalent in modern society) followed by verbs (splashed, committed). This step is mostly used to grab the attention of the reader. Hyland (1990) claimed this step as a Gambit move and it was an optional move. Like Hyland, this move was not frequently used by the students in producing argumentative essays.

Table 3 Examples of linguistic features and sentences signalling Move 1 Steps

Example (Sample number)
Just flip open the newspapers and turn on the news channel on television and
you'll see reports of crimessplashed all over media. (B5AE_5)
It is in actual fact quite amazing how some of the outrageous crimescommitted
were unheard of in the olden days, but have become so prevalent in modern
society that many people do not even bat an eyelid when we hear of those crimes.
(B5AE_3)

Table 4 showed the steps involved in shaping the second move, namely Providing background information. For the first step (S1a: Defining the key word (s)/theme) words like 'defined', 'obtain' and 'achieve' were used to define the key words. The next step (S1b: Stating an expert's/ leader's opinion or contribution/actions) signaled by some experts names (Nelson Mandela, Mahatma Gandhi, Sir Issac Newton) and their contributions (conquest for freedom, search for freedom, create his light bulb) which were written to support the topic. The last step is S1c: Providing driving questions to contextualize the topic/issue which was signaled by 'how humans could hurt another human' and 'have we stopped and tried'. This driving question step would probably provoke the readers' mind to build new information using their prior knowledge. In short, students believed that these steps would provide some information to the readers and enable them to contextualize the topic of discussion. 
Table 4 Examples of linguistic features and sentences signalling Move 2 Steps

\begin{tabular}{|c|c|}
\hline Example (Sample number) & Steps \\
\hline $\begin{array}{l}\text { In simple terms, success can be defined as attaining the things that make you } \\
\text { happy. (B5AE_5) }\end{array}$ & 1b. Defining the key word (s)/theme \\
\hline \multicolumn{2}{|l|}{$\begin{array}{l}\text { Success is being able to obtain or to achieve what you want at a specific time with } \\
\text { full efforts. B4AE_3) }\end{array}$} \\
\hline $\begin{array}{l}\text { The great Nelson Mandela did not achieve his mission overnight. He suffered an } \\
\text { arduous battle in his conquest for freedom. (B4AE_7) }\end{array}$ & $\begin{array}{l}\text { 1c. Stating an expert's/ leader's opinion or } \\
\text { contribution/actions }\end{array}$ \\
\hline \multicolumn{2}{|l|}{$\begin{array}{l}\text { Mahatma Gandhi pursued his non-violent battle with the British in search of } \\
\text { freedom. (B5AE_2) }\end{array}$} \\
\hline \multicolumn{2}{|l|}{$\begin{array}{l}\text { And imagine if Sir Isaac Newton had not tried repeatedly to create his light bulb. } \\
\text { (B5AE_4) }\end{array}$} \\
\hline $\begin{array}{l}\text { While gruesome details of the crime and photos of the crime scene are being laid } \\
\text { out before us and we get all appalled at how humans could hurt another human } \\
\text { being in such an inhumane way, have we stopped and tried to work our way to } \\
\text { the very root of this problem of the never ending crimes? (B6AE_3) }\end{array}$ & $\begin{array}{l}\text { 1d. Providing driving questions to contextualize the } \\
\text { topic/issue }\end{array}$ \\
\hline
\end{tabular}

As shown in Table 5, the first step of this move is S3a: Stating a stand or a position. The first step of this move is S3a: Stating a stand or a position.Argumentative essay requires the writers to announce their position by stating a stand whether the writers agree, disagree or partially agree with the topic given. This step can be written in various ways, but the participants in this study used some linguistic features to shape it. For example, phrases like 'clearly observe' and 'partially agree'. Followed by the next step (S3b: Indicating reasons or main ideas), which was realized based on the noun phrases (one's own perseverance, hard work and discipline attitude, wisdom of independence and passion). Here, the writers would introduce at least three reasons to support the previous step (stating a stand or position) in a form of a sentence. In other words, it is known as a thesis statement. This statement is crucial to guide the writer as well as the readers in writing and reading the essay.

Table 5 Examples of linguistic features and sentences signalling Move 3 Steps

\begin{tabular}{ll}
\hline Example (Sample number) & Steps \\
\hline
\end{tabular}

In short, we can clearly observe that it is the individuals themselves who 3a. Stating a stand or a position contribute to their own success... (B5AE_2)

I partially agree with the statement that the most important factor which contributes towards a person's success is himelf. (B5AE_4)

In the same manner, albeit we may not attain success in such a drastic level, we 3b. Indicating reasons or main ideas (at least 3 ) all can take heed that success is determined by one's own perseverance, hard work and discipline(B5AE_5)

The success mentioned can be discussed in terms of attitude, wisdom of independence and passion..(B5AE_2)

Subsequently, Table 6 showed the second stage is Argument or commonly known as body paragraph(s) in the argumentative essays. The findings revealed that, in this stage, Band 4, 5 and 6 writers utilized three moves, namely 'Establishing topic sentence', 'Justifying the main idea', and 'Drawing a conclusion'. These moves were found to be contradictory to Hyland's model as Marker move and Restatement move were not recognized. Since the argumentative essay requires three main ideas or reasons to support the writer's position, the identified moves in the argument stage could be used repeatedly to develop each main idea into a paragraph. 
Table 6 Rhetorical structure of argument stage

\begin{tabular}{ll}
\hline Stage & Moves \\
\hline Argument & Move 4:Establishing topic sentence \\
Steps & \\
4a. Introducing a main idea to support the stand & Move 5: Justifying the main idea \\
Steps & 5a. Providing reasons to support the main idea \\
5b. Describing the reasons \\
5c. Providing examples or evidences to support the reason and the main idea \\
5d. Indicating expert's opinion or contribution and relating it to the reason or main idea \\
Move 6: Drawing conclusions \\
Steps \\
6a. Restating the main idea
\end{tabular}

Based on Table 7, 'S4a: Introducing a main idea to support the stand', was the only step that formed Move 4. This was signaled by the discourse markers (first and foremost, to begin with and another important criterion). This step is important as it signals the main idea that will be discussed throughout the paragraph. Hyland (1990) had claimed these discourse markers alone as moves, but the researchers in this study believed that the discourse markers were used to signal the main idea that would be developed into a paragraph. Each marker carries a meaning that is to signal the ideas in the paragraphs in order to retain the cohesion of the essay.

Table 7 Examples of linguistic features and sentences signalling Move 4 Steps

\begin{tabular}{|c|c|}
\hline Example (Sample number) & Steps \\
\hline $\begin{array}{l}\text { First and foremost, effort and determination from oneself plays an important role } \\
\text { as to drive us towards success.(B5AE_2) }\end{array}$ & 4a. Introducing a main idea to support the stand \\
\hline $\begin{array}{l}\text { To begin with, an individual with the right attitude will most assuredly be heading } \\
\text { in the direction of success. (B5AE_4) }\end{array}$ & \\
\hline $\begin{array}{l}\text { Yet another important criterion to be aware of is to be able to support oneself, } \\
\text { without relying on others and being able to make the wisest decisions. (B5AE_4) }\end{array}$ & \\
\hline
\end{tabular}

Table 8 showed the steps involved in shaping the fifth move, namely 'Justifying the main idea'. For the first step 'S5a: Providing reasons to support the main idea',phrases like 'is important', 'probably because' were used to provide reasons to support the argument. The next step (S5b: Describing reasons) signaled by phrases like 'indulging and embarking' and 'research has always proven'. This step would provide some detailed explanation based on reason given from the previous step and further retain the cohesion of the paragraph. The following step would be 'S5c: Providing examples or evidences support the reason and the main idea'. Here, the writers would enlighten the readers by providing some specific examples, like statistics or even situations to back up the main idea and the reasons provided. This would strengthen the justification made by the writers. This particular step was signaled by phrases like 'for instance' and 'for example'. The last step is 'S1c: Indicating expert's opinion or contribution and relating it to the reason and main idea'. The linguistic feature that signaled this step was the expert's name 'Mr. Thomas Alva Edison'which was written to support the argument.

Table 8 Examples of linguistic features and sentences signalling Move 5 Steps

Example (Sample number)
Concentration is important to kill such thoughts as they only come across as
obstacles in search of the real goal. (B4AE_10)
This is most probably because when directed with a vision of the desired success,
the individual becomes more motivated to accomplish the success he has set in his
mind. (B4AE_8)
Indulging and embarking on unnecessary events will diverge away from your
goal is not going to be much of a help. (B5AE_10)
Research has always proven unquestionably that the human mind is much more
efficient when directed or driven by goals. (B5AE_4)
efficient when directed or driven by goals. (B5AE_4)

For instance, a person who is perseverant will not give up although there have been many failed attempts or setbacks. (B5AE_4) 5a. Providing reasons to support the main idea

5b. Describing the reasons

5c. Providing examples or evidences to support the reason and the main idea

5d. Indicating expert's opinion or contribution and relating it to the reason or main idea 
For example, two fresh graduates who are friends have been studying together during their undergraduate programme and both have achieved first class honour. (B5AE_2)

Let us have a look at a successful individual, Mr. Thomas Alva Edison, famous for his invention of the light bulb, which has brought about many other inventions and modifications especially in the technology we use today.Can you imagine the world if he hadn't been perseverant and instead had given up after being ridiculed? (B5AE_4)

Based on Table 9, the step for Move 6 (S6a: Restating the main idea) was signaled by discourse markers like 'hence', 'it can be concluded' and 'therefore'. This indicated that each paragraph in the argument stage should be summarized. Therefore, the usage of suitable discourse markers would guide the readers before they moved to another stage

Table 9 Examples of linguistic features and sentences signalling Move 6 Steps

Example (Sample number) Steps

$\underline{\text { Hence, }}$ effort really plays a crucial role in achieving success. (B5AE_2)

6a. Restating the main idea

It can be concluded, therefore that since it is a factor of survival, and success is the key to survival, that in order to succeed, one has to be wise in being independent and taking chances. (B5AE_4)

The final stage as shown in Table 10 is Conclusion. In this stage, Hyland had reported four moves; Marker, Consolidation, Affirmation and Close. However, after analyzing the learner corpus, the present study has revealed that the Band 4, 5 and 6 writers composed this stage by employing three moves (Consolidating the argument, Affirming the position and Recommending an action).

Table 10 Rhetorical structure of conclusion stage

\begin{tabular}{l} 
Stage Moves \\
\hline Conclusion $\quad$ Move 7:Consolidating the argument \\
Move 8: Affirming the position \\
Steps $\quad$ 8a. Restating the thesis statement \\
Move 9:Recommending an action \\
Steps \\
9a. Indicating some actions to be taken by authorities
\end{tabular}

Based on Table 11, Move 7 (Consolidating the argument) was signaled by discourse markers like 'in conclusion', 'to sum up'. This indicated that the concluding paragraph should be strengthened by referring back to the content of the argument and relate to the topic.. Therefore, the usage of suitable discourse markers would guide the readers before moving to another stage.

Table 11 Examples of linguistic features and sentences signalling Move 7

\section{Example (Sample number)}

In conclusion, being successful is not about earning a lot of money and what not.

Consolidating the argument Success in the perspective of different individuals stands for different ways.(B5AE_2)

To sum up, the success of an individual is directly affected by the individuals themselves in terms of how they act, think and perceive.(B5AE_4) 
The first step of this move as shown in Table 12 is 'S8a: Restating the thesis statement'. The participants in this study used some linguistic features to shape it. For example, phrases like 'all three' 'have mentioned earlier' and 'these can be observed'. Here, the writers would recap by listing the three reasons stated in M3S3b.

Table 12 Examples of linguistic features and sentences signalling Move 8 Steps

\begin{tabular}{l}
\hline Example (Sample number) \\
\hline In all three points; attitude, wisdom of independence and passion, that I have $\quad$ 8a. Restating the thesis statement \\
mentioned in the earlier paragraphs, each of them have a vivid correlation to \\
the ability of the individual himself to determine his future. (B5AE_2) \\
$\underline{\text { These can be observed by a person's attitude, wisdom in decision-making, and }}$ \\
passion. (B5AE_4)
\end{tabular}

Based on the step 'S9a: Indicating some actions to be taken' shown in Table 13, Move 9 (Recommending an action) was realised. This step was signaled by modal verbs such as 'must' and a noun phrase 'all you need'. Like Imtiaz and Mahmood (2014), this move was identified as a new move, which did not exist in Hyland's model.

Table 13 Examples of linguistic features and sentences signalling Move 9 Steps

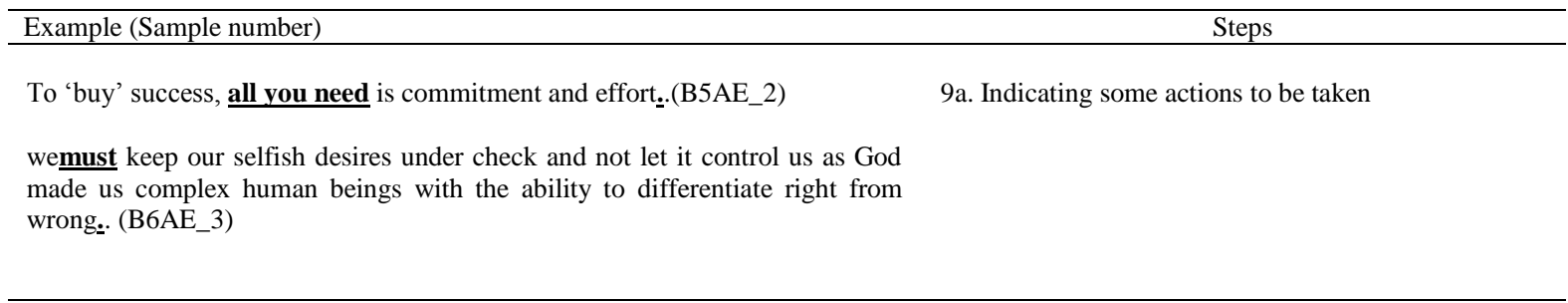

\subsection{CONCLUSION}

The major concern of this study was to analyse the move patterns and steps employed in argumentative essays by pre-university students. Most of the previous researchers had not paid much attention to develop the rhetorical structure of an argumentative essay, thus to fill this gap Hyland's model was adopted to assist the move identification. In this study, the argumentative essays were analysed structurally to distinguish the moves. It was obvious that Band 4, 5 and 6 writers, in Malaysia used some new moves which did not exist in the model, especially in the argument stage and conclusion stage. As a whole, the researchers identified a total of 9 moves and 14 steps in composing an argumentative essay. Though it was done qualitatively, corpus-based analysis had eased the process of identifying as it was not only saved the researchers' time and cost, but reduces the probability of human errors. Apart from that, using this computer based method is also beneficial for English teachers who are looking for a quick and easy approach for assessing their students' writing ability.

Pedagogically, this study has a few significant pedagogical implications for the teachers and students both in theoretical and practical aspects. The identified moves can provide a greater picture of how Band 4, 5 and 6 writers compose a good essay. The list of moves can offer a better guideline for teachers, especially at pre-university colleges in producing competent writers who are being able to communicate effectively as writing is essential at tertiary level as well as workplace. Furthermore, it can also offer a platform for the students to understand their weaknesses and strengths of writing an argumentative essay and find ways to improvise their written product with an effective intervene. In the same vein, the moves and steps can be employed as a scaffolding tool to guide the students to produce their own piece of writing.

Nevertheless, the present study had focused only on a small sample of a learner corpus. Therefore, the findings probably were not suitable for generalization on a larger corpus. A quantitative approach should also be adopted in line with corpus-based approach. Future research could be conducted using a combination of qualitative and quantitative approach with a larger corpus as it would give a holistic finding.

\section{Acknowledgement}

The authors acknowledge the support of Research Acculturation Collaborative Effort (RACE) Grant Scheme (S/O Code:13161).

\section{References}


Abdollahzadeh, E. \&Salarvand, H. (2013). Book Prefaces in Basic, Applied and Social Sciences: A Genre Based Study. WASJ 28(11), 1618-1626.

Ali, S., Muhammad, Z. \& Asim, M. (2015). A Genre Analysis of Preface Sections of Textbook. Journal Education and Practice, 6(7), 58-64.

Bahtia, V.K. (1993). Analysing Genre: Language Use in Professional Settings. London: Longman.

Choe, H., \& Hwang, B. H. (2014). A Genre Analysis of Introductions in Theses, Dissertations and Research Articles Based on Swales '. Korean Journal of Applied Linguistic, 1, 3-31.

Connor, U. \& Mauranen, A. (1999). Linguistic Analysis Of Grant Proposal: European Union Research Grants. English for Specific Purposes, 18, 47-62.

Connor, U. (2002). New Directions in Contrastive Rhetoric. TESOL Quaterly, 36(4), 493-510.

Elashri, I. (2013). The Effect Of The Genre-Based Approach To Teaching Writing On The EFL Al-Azhr Secondary Students' Writing Skills And Their Attitudes Towards Writing, 1-58.

Hyland, K. (1990). A Genre Description of the Argumentative Essay. RELC Journal, 21 (1), 67-78.

Imtiaz, Z. \& Mahmood, A. (2014). Genre Analysis of Argumentative Essays of Pakistani EFL Learners. Journal of Education and Practice, 5(30), 95-101.

Ina, S., Aizan, Y., \& Noor Hashima, A. A. (2015). Introduction Sections Of Research Articles With High And Low Citation Indices. Pertanika Journal of Social Sciences and Humanities, 23(4), 1139-1152.

Kanoksilapatham, B. (2003). A Corpus-Based Investigation Of Biochemistry Research Articles: Linking Move Analysis With Multidimensional Analysis. Unpublished Ph.D. Dissertation. Georgetown University.

Liu, D. (2015). Moves and Wrap-up Sentences in Chienese students’ Essay Conclusions. SAGE,1-9. DOI: 10.1177/2158244015592681.

Manvender, K. (2014). A Corpus-Based Genre Analysis Of Quality, Health, Safety And Environment Work Procedures In Malaysian Petroleum Industry.Unpublished Doctoral Thesis. Malaysia: Universiti Teknologi.

Manvender, K. Yasmin, H.Z., \& Sarimah, S. (2012). A Computer-Assisted Corpus Analysis (CACA) of Professional Discourse. Sino-US English Teaching, 9(6), 12361245 .

Maswana, S., Kanamaru, T., \& Tajino, A. (2015). Move Analysis Of Research Articles Across Five Engineering Fields: What They Share And What They Do Not. Ampersand, 2, 1-11. http://dx.doi.org/10.1016/j.amper.2014.12.002

Matsuda, P. K. (1997). Contrastive Rhetoric in Context: A Dynamic Model of L2 Writing, Journal of Second Language Writing, 6(1), 46-60.

Misyana, S.H., \& Kamisah, A. (2012). The Rhetorical Organisation of English Argumentative Essays by Malay ESL Students: The Placement of Thesis Statement. The Journal Asia TEFL, 9(1), 147-169.

Nodoushan, M. A. S., \& Montazeran, H. (2012). The Book Review Genre: A Structural Move Analysis. International Journal of Language Studies, 6(1), 1-30.

Reza, P. \& Atena, A. (2013). Rhetorical patterns of argumentation in EFL journals of Persian and English. International Journal of Research Studies in Language Learning, 2(1), 81-90,

San, L. Y., \& Tan, H. (2012). A Comparative Study Of The Rhetorical Moves In Abstracts Of Published Research Articles And Students' Term Papers In The Field Of Computer And Communication Systems Engineering. International Journal of Applied Linguistics and English Literature, 1(7), 40-50. http://doi.org/10.7575/ijalel.v.1n.7p.40

Swales, J. (1981). Aspects of Article Introductions. Birmingham AL: University of Aston.

Swales, J. M. (1990). Genre Analysis: English In Academic And Research Settings. Cambridge: Cambridge University Press.

Tseng, F. (2011). Analyses of Move Structure and Verb Tense of Research Article Abstracts in Applied Linguistics. International Journal of English Linguistics, 1(2), 27-39. http://doi.org/10.5539/ijel.v1n2p27

Vahid, N., Zahra, T., Sara, S. P., \&NurIzyanSyamimi, M. H. (2016). Rhetorical Moves in Problem Statement Section of Iranian EFL Postgraduate Students' Theses. Advances in Language and literary Studies, 7(4), 173-180. 